\title{
Positive correlation of serum leptin with estradiol levels in patients with polycystic ovary syndrome
}

H.C. Mendonça ${ }^{1}$, R.M. Montenegro ${ }^{2}$,

M.C. Foss ${ }^{2}$, M.F. Silva de Sá ${ }^{1}$ and R.A. Ferriani ${ }^{1}$
${ }^{1}$ Departamento de Ginecologia e Obstetrícia, and

${ }^{2}$ Divisão de Endocrinologia e Metabologia, Departamento de Clínica Médica, Hospital das Clínicas, Faculdade de Medicina de Ribeirão Preto, Universidade de São Paulo, Ribeirão Preto, SP, Brasil

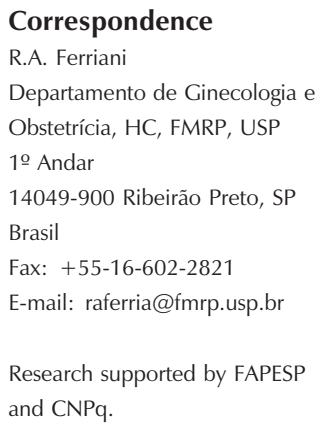

Received February 27, 2003 Accepted January 5, 2004

\begin{abstract}
Patients with polycystic ovary syndrome (PCOS) usually are obese, insulin resistant and hyperinsulinemic. The known association between leptin, obesity and insulin action suggests that leptin may have a role in PCOS but this has only been addressed peripherally. This study was designed to assess the relationship between serum leptin and the anthropometric, metabolic and endocrine variables of obese (body mass index, BMI $\geq 30 \mathrm{~kg} / \mathrm{m}^{2}$ ) and non-obese (BMI $<30 \mathrm{~kg} / \mathrm{m}^{2}$ )

PCOS patients. Twenty-eight PCOS patients and 24 control women subdivided into obese and non-obese groups were evaluated. Leptin, androgens, lipids, gonadotrophins and insulin-glucose response to the oral glucose tolerance test were measured by radioimmunoassay in all participants. The assays were done all in one time. The areas under the insulin curve (AUC-I) and the glycemia curve were calculated to identify patients with insulin resistance. Mean leptin levels were not significantly higher in patients with PCOS compared to the control group $(21.2 \pm 10.2 v s 27.3 \pm 12.4 \mathrm{ng} / \mathrm{ml})$. Leptin levels were found to be significantly higher in the obese subgroups both in patients with PCOS $(26.9 \pm 9.3$ vs $14.1 \pm 7.0 \mathrm{ng} / \mathrm{ml})$ and in the control group $(37.3$ \pm 15.5 vs $12.9 \pm 5.8 \mathrm{ng} / \mathrm{ml})$. The leptin of the PCOS group was correlated with BMI $(\mathrm{r}=0.74 ; \mathrm{P}<0.0001)$ and estradiol $(\mathrm{r}=0.48 ; \mathrm{P}<$ $0.008)$ and tended to be correlated with the AUC-I $(r=0.36 ; \mathrm{P}=0.05)$. Of the parameters which showed a correlation with leptin in PCOS, only estradiol and probably insulinemia (AUC-I) did not show a significant correlation with BMI, suggesting that the other parameters were correlated with leptin due to their correlation with BMI. Estradiol correlated with leptin in PCOS patients regardless of their weight.
\end{abstract}

Key words - Leptin

- Polycystic ovary syndrome

- Insulin

- Insulin sensitivity

- Estrogen

\section{Introduction}

The polycystic ovary syndrome (PCOS) affects approximately $5-10 \%$ of women of reproductive age and is characterized by menstrual disorders, chronic anovulation and hyperandrogenism (1). About 50-60\% of PCOS patients are obese, hyperinsulinemic and insulin resistant (2). A relationship between body weight and reproductive function has been observed. Women with low body fat stores such as dancers, Olympic 
runners and those with nervous anorexia frequently show infertility. At the other end of the spectrum, obese women present an elevated incidence of oligomenorrhea or amenorrhea and infertility (3). The discovery of leptin (4) opened new perspectives about the relation between body fat and menstrual disorders. Leptin is secreted by adipocytes in proportion to the amount of body fat and exerts a potent inhibitory action on food intake. In humans, serum leptin concentrations correlate positively with percent body fat. Weight loss and fat reduction are associated with lower levels of serum leptin $(5,6)$. This suggests that obesity, rather than being caused by deficient leptin production in the adipose tissue, may be caused by resistance to leptin due to an alteration in its receptor, which would hinder the action of central mechanisms responsible for the reduction of appetite (5).

The very close association between hyperinsulinemia and hyperleptinemia suggests that expression of the $o b$ gene, which codes for leptin, may be mediated by insulin both in humans and in rats (7). In addition, it has been suggested that insulin indirectly regulates leptin secretion due to its trophic effect on the adipocytes (8).

Thus, insulin, leptin, body weight, ovarian steroidogenesis and ovulation show complex interrelations. According to Poretsky et al. (9), it appears that insulin stimulates leptin secretion, increases the pituitary gonadotrophin response to gonadotrophin-releasing hormone $(\mathrm{GnRH})$ and promotes steroidogenesis. Leptin stimulates all levels of the reproductive axis, i.e., hypothalamus, pituitary and ovary. In view of these effects, the possibility was raised that high levels of leptin may contribute to the physiopathology of PCOS (10), although others report that the significance of the increase is lost when leptin concentrations are adjusted for body mass index (BMI) (11-13). Since obesity exerts complex effects on glucose tolerance and insulin sensitivity, it is necessary to control these effects by separately studying groups of obese and non-obese PCOS patients and comparing them to control groups of obese and non-obese ovulatory women.

The aim of the present study was to determine the relationship between serum leptin and estradiol and investigate the potential association with BMI, waist:hip ratio (WHR) and insulin resistance calculated by area under the insulin curve (AUC-I) in PCOS patients and weight-matched ovulatory women.

\section{Material and Methods}

\section{Patients}

In this prospective clinical study, 52 women of reproductive age (16-43 years) were allocated to four groups: 13 obese women with PCOS (BMI $\left.\geq 30 \mathrm{~kg} / \mathrm{m}^{2}\right), 13$ obese controls, 15 non-obese women with PCOS (BMI $<30 \mathrm{~kg} / \mathrm{m}^{2}$ ), and 11 non-obese controls. The PCOS patients were selected at the Endocrine Gynecology Outpatient Clinic of a public institution. The controls were volunteers who freely agreed to participate in the study. All women gave informed written consent before participating in the study, which was approved by the Ethics Committee of the Hospital.

\section{Inclusion and exclusion criteria}

PCOS group. Twenty-eight women with amenorrhea or oligomenorrhea (six or less menses/year) associated with signs of clinical and/or laboratory hyperandrogenemia according to NIH criteria (1990). Clinical hyperandrogenemia involves hirsutism (Ferriman index $\geq 8$ ) and elevated serum testosterone or androstenedione levels. Congenital adrenal hyperplasia was excluded after serum measurement of dehydroepiandrosterone (DHEAS, cut-off $350 \mu \mathrm{g} / \mathrm{dl}$ ) and 17-hydroxyprogesterone $(17-\mathrm{OH}$, cutoff $180 \mathrm{ng} / \mathrm{dl}$ ).

Control group. Twenty-four ovulatory 
women with regular menstrual cycles (serum progesterone $>5 \mathrm{ng} / \mathrm{ml}$ on the $22 \mathrm{nd}$ day of the cycle) and no clinical signs of hyperandrogenemia.

Women submitted to hormonal or oral contraceptive treatment during the 3 months preceding the study or with hyperglycemia, thyroid or prolactin alterations were excluded from the study.

\section{Anthropometric assessment}

Weight was assessed on the basis of BMI (14) calculated by dividing weight (in kilograms) by the height squared. Patients and controls were subgrouped as obese (BMI $\geq 30 \mathrm{~kg} / \mathrm{m}^{2}$ ) and non-obese (BMI $<30 \mathrm{~kg} /$ $\mathrm{m}^{2}$ ). To indirectly assess body fat distribution we adopted the WHR.

\section{Oral glucose tolerance test}

After a 12-14-h fast, $75 \mathrm{~g}$ dextrose was administered orally to all participants and blood was collected every $30 \mathrm{~min}$ over a period of $2 \mathrm{~h}$ for the measurement of glucose and insulin. Insulin resistance was determined indirectly by calculating the AUC-I and the area under the glycemia curve (AUC$\mathrm{G})$ and the ratio of the two curves was taken to be AUC-I/AUC-G.

\section{Hormonal and biochemical tests}

The analyses were carried out during the follicular phase in women who had menstrual periods and in any phase of the cycle in the amenorrheic PCOS patients. The subjects were instructed to ingest an amount of calories adequate for their daily energy needs, with at least $200 \mathrm{~g}$ carbohydrates, for a minimum period of 3 days before the test. Blood samples were collected for the analysis of leptin, testosterone, androstenedione, luteinizing hormone $(\mathrm{LH})$, follicle-stimulating hormone (FSH), estradiol $\left(\mathrm{E}_{2}\right)$, total cholesterol, HDL, LDL, and triglycerides. All samples were centrifuged and stored at $-20^{\circ} \mathrm{C}$ until the assay.

All determinations for each experiment were made in a single assay. Leptin was assayed by radioimmunoassay (RIA; LINCO Research Inc., St. Charles, MO, USA) with a $5.7 \%$ intra-assay error and a mean value of $20.4 \pm 7.8 \mathrm{ng} / \mathrm{ml}$ for control population. Insulin was assayed in duplicate by solid phase RIA (double antibody) and the results are reported as $\mu \mathrm{U} / \mathrm{ml}$. The minimum amount of insulin detected was $1.0 \mu \mathrm{U} / \mathrm{ml}$. Intra- and interassay coefficients of variation were 5.5 and $16.5 \%$, respectively. Androstenedione, testosterone, DHEAS, and 17-OH were also assayed by RIA. LH, FSH, prolactin, $\mathrm{E}_{2}$, progesterone $\left(\mathrm{P}_{4}\right)$, thyroid-stimulating hormone and free thyroxine $\left(\mathrm{T}_{4}\right)$ were assayed by chemiluminescence (DPC, Los Angeles, CA, USA). Plasma glucose was measured by the glucose oxidase method. Total cholesterol and triglycerides were determined by enzymatic methods using Dimension kits (Dade Behring, Newark, DE, USA) and HDL cholesterol was determined by phosphotungstate-magnesium chloride precipitation.

On the 22nd day of the cycle, $\mathrm{P}_{4}$ was measured in normal volunteers in order to confirm the ovulatory condition. All subjects were submitted to pelvic ultrasound always in the first phase of the menstrual cycle, transvaginally whenever possible, using an ATL-HDI 2000 instrument (ATL, Bothell, WA, USA) and a 5000-13000-MHz transducer, in order to assess ovarian morphology, with emphasis on the presence of multiple cysts $\leq 8 \mathrm{~mm}$ in diameter.

\section{Statistical analysis}

Data are reported as medians, means and standard deviation. The normality criteria used to interpret the glucose curves were those of the American Diabetes Association (15). AUC-G and AUC-I were calculated using the trapezoid rule. Data were analyzed statistically by the nonparametric Kruskal- 
Wallis test for comparison of the medians and by analysis of variance (ANOVA) for comparison of the means. When necessary, logarithmic or mean square root transformation of the data was carried out. The StudentNewman-Keuls test was used for inter-mean discrimination. Simple Spearman linear correlation and regression were used to determine the correlation between variables for the four groups. The level of significance was set at $\mathrm{P}<0.05$ for all analyses.

\section{Results}

\section{PCOS group versus the control group}

The clinical and metabolic characteristics of all subgroups (obese and non-obese women with PCOS and obese and non-obese controls) are listed in Table 1. When analyzed as a group, PCOS patients (obese and non-obese) had similar BMI to that of control women (obese and non-obese), but PCOS women were younger, had significantly higher concentrations of LH, LH/FSH, testosterone, and androstenedione, and a higher degree of insulin resistance. Approximately
$68 \%$ of the PCOS patients presented hirsutism and $75 \%$ presented insulin resistance ( $78.6 \%$ of obese patients and $71.4 \%$ of nonobese patients). There was no difference between groups in lipid profile or total cholesterol/HDL index in spite of body weight. Mean serum leptin levels were similar in patients with PCOS and controls (21.2 \pm 10.2 vs $27.3 \pm 12.4 \mathrm{ng} / \mathrm{ml}$, respectively). When mean serum leptin levels were compared between obese and non-obese women in both groups, they were significantly higher in the obese women $(32.2 \pm 9.3 \mathrm{ng} / \mathrm{ml}$ vs 13.5 $\pm 6.8 \mathrm{ng} / \mathrm{ml}$; Figure 1).

Correlation analyses were performed between leptin levels and all other parameters. There was a significant positive correlation between serum leptin levels and BMI both in the PCOS group and in the control group $(\mathrm{r}=$ 0.74; $\mathrm{P}<0.0001$ and $\mathrm{r}=0.82 ; \mathrm{P}<0.0001$, respectively). Nevertheless, when obese and non-obese subjects were compared this correlation was demonstrable only for the obese groups (PCOS patients: $\mathrm{r}=0.74 ; \mathrm{P}<0.05$, and controls: $\mathrm{r}=0.54 ; \mathrm{P}<0.05)$ but not in the non-obese groups (PCOS patients: $\mathrm{r}=0.28$; $\mathrm{P}>0.05$, and control group: $\mathrm{r}=0.10 ; \mathrm{P}>$

Table 1. Clinical and metabolic characteristics of the groups studied.

\begin{tabular}{|c|c|c|c|c|}
\hline \multirow[t]{2}{*}{ Variable } & \multicolumn{2}{|c|}{ Obese } & \multicolumn{2}{|c|}{ Non-obese } \\
\hline & $\operatorname{PCOS}(N=13)$ & Control $(N=13)$ & $\operatorname{PCOS}(N=15)$ & Control $(N=11)$ \\
\hline Age (years) & $23.5 \pm 4.5^{a}$ & $32.1 \pm 5.6^{b}$ & $20.0 \pm 5.2^{\mathrm{a}}$ & $30.0 \pm 6.3^{b}$ \\
\hline $\mathrm{BMI}\left(\mathrm{kg} / \mathrm{m}^{2}\right)$ & $35.6 \pm 6.2^{a}$ & $39.8 \pm 7.6^{a}$ & $23.2 \pm 2.3^{b}$ & $22.3 \pm 2.2^{b}$ \\
\hline Waist $(\mathrm{cm})$ & $99.0 \pm 12.4^{a}$ & $103.8 \pm 9.7^{a}$ & $74.3 \pm 7.3^{b}$ & $74.7 \pm 6.2^{b}$ \\
\hline Waist:hip ratio & $0.85 \pm 0.06^{a}$ & $0.83 \pm 0.07^{a}$ & $0.77 \pm 0.03^{b}$ & $0.76 \pm 0.04^{b}$ \\
\hline $\mathrm{FSH}(\mathrm{mlU} / \mathrm{ml})$ & $4.3 \pm 1.0^{\mathrm{a}}$ & $6.4 \pm 2.5^{b}$ & $4.4 \pm 1.0^{a}$ & $4.7 \pm 1.7^{a}$ \\
\hline $\mathrm{LH}(\mathrm{mlU} / \mathrm{ml})$ & $7.4 \pm 2.9^{a}$ & $3.0 \pm 1.7^{b}$ & $8.4 \pm 5.2^{a}$ & $3.8 \pm 3.0^{b}$ \\
\hline LH/FSH & $1.7 \pm 0.8^{a}$ & $0.5 \pm 0.4^{b}$ & $1.9 \pm 0.8^{a}$ & $0.8 \pm 0.5^{b}$ \\
\hline$E_{2}(p g / m l)$ & $35.3 \pm 12.9^{a}$ & $29.2 \pm 7.3^{a}$ & $30.5 \pm 10.5^{a}$ & $35.0 \pm 21.6^{a}$ \\
\hline Testosterone (ng/dl) & $106.7 \pm 42.8^{a}$ & $46.0 \pm 20.2^{b}$ & $92.0 \pm 31.9^{a}$ & $51.4 \pm 18.8^{b}$ \\
\hline Androstenedione (ng/dl) & $225.3 \pm 69.8^{a}$ & $104.1 \pm 59.6^{b}$ & $228.7 \pm 70.8^{a}$ & $130.2 \pm 65.2^{b}$ \\
\hline Fasting plasma glucose (mg/dl) & $78.0 \pm 10.4^{a}$ & $87.3 \pm 8.8^{b}$ & $76.8 \pm 7.2^{a}$ & $81.9 \pm 7.9^{b}$ \\
\hline Fasting serum insulin $(\mu \mathrm{U} / \mathrm{ml})$ & $23.8 \pm 13.6^{a}$ & $17.1 \pm 7.2^{\mathrm{a}}$ & $14.9 \pm 7.9^{a}$ & $7.9 \pm 3.6^{b}$ \\
\hline$A \cup C-I / A \cup C-G$ & $1.47 \pm 0.6^{a}$ & $0.75 \pm 0.2^{b}$ & $1.40 \pm 0.8^{a}$ & $0.53 \pm 0.2^{c}$ \\
\hline
\end{tabular}

Data are reported as means \pm SD. AUC-G = area under the curve for glucose; AUC-I = area under the curve for insulin; $\mathrm{BMI}=$ body mass index; NS = not significant; $\mathrm{PCOS}$ = polycystic ovary syndrome. See text for other abbreviations. Means followed by different letters differed significantly $(P<0.05$, Kruskal-Wallis test and ANOVA). 
$0.05)$.

There was a positive and significant correlation between leptin levels and waist measurement, $E_{2}$ and AUC-G in PCOS patients (Table 2), but no correlation between leptin and AUC-I, WHR, LH, FSH, testosterone, androstenedione, total cholesterol, HDL-cholesterol, LDL-cholesterol and AUC-I/AUC$\mathrm{G}$. There was a trend of correlation between leptin and AUC-I. Of the parameters which showed a correlation with leptin in PCOS, only estradiol did not show a significant correlation with BMI, suggesting that the other parameters correlated with leptin only because of their correlation with BMI.

In the control group, leptin levels correlated positively with waist measurement $(\mathrm{r}=$ 0.82; $\mathrm{P}<0.05)$ and AUC-I $(\mathrm{r}=0.54 ; \mathrm{P}<$ $0.01)$ but not with AUC-G $(P=0.05)$. However, all of these parameters correlated significantly with BMI, suggesting that these correlations were due only to BMI.

LH and the LH/FSH ratio correlated negatively with leptin in the obese group as a whole $(\mathrm{r}=-0.56 ; \mathrm{r}=-0.49)$ and in the obese PCOS patients $(r=-0.69 ; r=-0.76)$.

\section{Discussion}

Leptin, an $o b$ gene product, is produced by the human fat body stores and appears to be involved in the regulation of the reproductive axis. In the present study we attempted to correlate leptin with PCOS taking into consideration body weight and several metabolic parameters. Our results confirm a positive correlation of leptin with body weight and waist measurement in humans (11-13). Brzechffa et al. (10) studied the effects of leptin on PCOS pathogenesis and observed higher concentrations of leptin in some women in spite of their BMI and sensitivity to insulin, suggesting that leptin signaling anomalies in the reproductive axis could be involved in the physiopathology of PCOS. Later studies (11-13) provided strong evidence against the report that leptin levels were elevated in PCOS women when compared to control groups (10) and affirmed that high leptin was the result of the high body weight of PCOS patients. Our findings that leptin levels were not higher in patients with PCOS compared to the control group and it was correlated with the amount of fat tissue not only in patients with PCOS but also in healthy women confirm these reports. However, our most interesting result was the correlation between leptin and $\mathrm{E}_{2}$.

We found a positive and statistically sig-

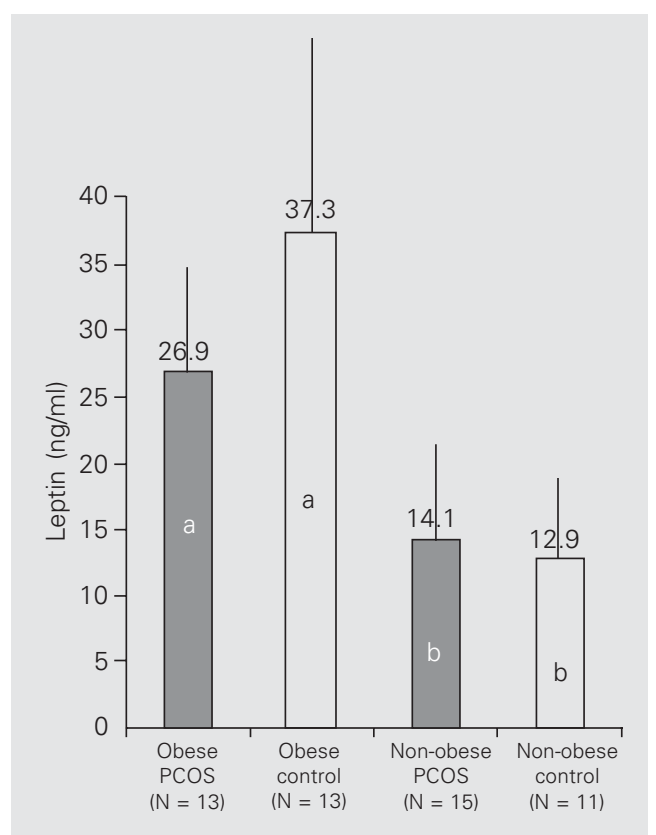

Figure 1. Serum leptin levels for the polycystic ovary syndrome (PCOS) and control groups according to body mass index. Data are reported as means \pm $\mathrm{SD}$. Means followed by different letters differed significantly $(\mathrm{P}<$ 0.05, Student-Newman-Keuls test).
Table 2. Anthropometric and metabolic measurements in 28 PCOS patients and their correlations with leptin and body mass index (BMI).

\begin{tabular}{|c|c|c|c|c|c|}
\hline \multirow[t]{2}{*}{ PCOS patients } & \multirow[t]{2}{*}{ Mean $\pm S D$} & \multicolumn{2}{|c|}{$\begin{array}{l}\text { Correlation } \\
\text { with leptin }\end{array}$} & \multicolumn{2}{|c|}{$\begin{array}{c}\text { Correlation } \\
\text { with BMI }\end{array}$} \\
\hline & & $\mathrm{r}$ & $P$ & $r$ & $P$ \\
\hline BMI $\left(\mathrm{kg} / \mathrm{m}^{2}\right)$ & $29.9 \pm 7.7$ & 0.74 & $<0.0001$ & - & - \\
\hline Waist $(\mathrm{cm})$ & $87.1 \pm 16.0$ & 0.69 & $<0.0001$ & 0.97 & $<0.0001$ \\
\hline Waist:hip ratio & $0.81 \pm 0.07$ & 0.37 & NS & 0.77 & $<0.0001$ \\
\hline$E_{2}(\mathrm{pg} / \mathrm{ml})$ & $34.8 \pm 11.8$ & 0.48 & $<0.008$ & 0.29 & NS \\
\hline Triglycerides (mg/dl) & $119.3 \pm 73.4$ & 0.31 & NS & 0.50 & 0.006 \\
\hline AUC-I & $18,232.5 \pm 11,324.2$ & 0.36 & NS & 0.27 & NS \\
\hline$A \cup C-G$ & $12,718.3 \pm 2,740.8$ & 0.43 & $<0.02$ & 0.39 & $<0.04$ \\
\hline Leptin (ng/ml) & $21.2 \pm 10.2$ & - & - & 0.74 & $<0.0001$ \\
\hline
\end{tabular}

Data are reported as means $\pm S D$. NS $=$ not significant $(P>0.05)$. For abbreviations, see legend to Table 1. The Spearman correlation and regression tests were used. 
nificant correlation between $\mathrm{E}_{2}$ and leptin, in agreement with Shimizu et al. (16) and Messinis et al. (17), suggesting that $\mathrm{E}_{2}$ can be an important regulator of leptin production in women. Nevertheless, our findings first showed a correlation of leptin with $\mathrm{E}_{2}$ in PCOS patients; also, this correlation was independent of BMI. We may speculate if the abnormal ovarian hormone milieu (elevated $\mathrm{E}_{2}$ levels) may have any influence on gonadotrophin secretion in PCOS patients via leptin action. In rats, elevated $\mathrm{E}_{2}$ levels enhanced leptin levels and neuropeptide $\mathrm{Y}$ expression and resulted in lower GnRH and gonadotropin secretion (18). In addition, altered fat distribution is a consequence of steroid metabolism, but the mechanisms responsible are unknown. Increased adiposity in ovariectomized rats can be reversed with 17beta-estradiol treatment (19), but this animal model suggests that obesity is not associated with hypoleptinemia or decreased $o b$ gene expression, but is associated with insensitivity to central leptin administration caused by estrogen deficiency. Women both in pre- and post-menopause have higher serum leptin levels than men $(20,21)$. Licinio et al. (22) have shown that women needed twice as leptin as men to maintain their normal weight. Estradiol may stimulate the production of leptin from the adipocytes (23). Leptin could act in the pituitary ovarian axis during fasting to improve reproductive function by partly stimulating estrogen secretion (23). Thus, the role of leptin in PCOS may occur by ways other than the simple concentration of the hormone in the circulation, and estrogen metabolism may be involved in this role.

On the other hand, in vitro studies do not corroborate these animal findings. A possible direct intra-ovarian effect of leptin was noted in a study on rats in which the action of insulin-like growth factor (IGF-1) and FSH on estradiol production by granulosa cells in culture was attenuated by the addition of leptin (24). It was shown that leptin inhibits
LH-stimulated $\mathrm{E}_{2}$ production by human granulosa cells in culture (25).

Studies in which 24-h LH pulses were observed in PCOS patients $(26,27)$ identified an inverse relationship between LH and BMI and between leptin and 24-h mean LH, suggesting that leptin could act at the hypothalamic or hypophyseal levels as a mediator for the negative feedback on LH secretion. Although we found a negative and significant correlation between leptin and LH levels in obese subjects as a whole and in obese PCOS patients, we did not find a significant correlation between LH and BMI in any of the groups.

Many obese women are hyperinsulinemic and insulin resistant $(28,29)$. Our data do not support this, since the obese group as a whole responded to insulin similarly to the non-obese women. Nevertheless, the PCOS patients presented higher insulin resistance than the control group. These results suggest that insulin resistance does not only depend on obesity but also on the presence of PCOS, as previously described (2). The results about the relation between leptin and insulin levels and insulin resistance are contradictory. Some investigators did not find any association $(5,30)$, indicating that other factors besides insulin are involved in the regulation of leptin concentration, whereas other studies have shown a positive association $(31,32)$. In the present study, we found a correlation between leptin and insulinemia probably explained by the correlation also found between insulinemia and BMI.

On average, control women were older than PCOS women, but the women in both groups were in the same phase of reproductive life, i.e., menacme, with no important difference between groups from an endocrine-gynecological point of view. In the present study, there was no correlation between serum leptin levels and age $(r=0.14$; $\mathrm{P}=0.32)$, in agreement with other studies $(10,33)$.

The lipid profile of the subjects studied 
here was normal. We observed only elevated triglycerides that were related to high BMI, independent of the presence of PCOS. Escobar-Morreale et al. (34), studying patients with hirsutism without PCOS, suggested that leptin may participate in the development of hyperandrogenemia. Brzechffa et al. (10) and Rouru et al. (35) found a correlation between leptin and free testosterone in PCOS patients. However, we did not observe a correlation between the androgens assayed in this study and leptin, in agreement with Spritzer et al. (36).

The fact that leptin levels are normal in a large proportion of women with PCOS does not exclude the possibility that leptin is involved in the pathophysiology of this syndrome. Although leptin values do not differ significantly between PCOS patients and controls, it is not known if body composition can affect leptin concentrations. On the other hand, leptin is secreted in a pulsatile way, and it is not known if the normal pattern of pulsatile secretion of leptin is altered in PCOS (37). Further studies are required to clarify the effects of leptin on the ovary and its possible pathophysiological role in PCOS.

The idea that circulating leptin concentrations in PCOS patients could differ from those of subjects with regular cycles was not confirmed in the present investigation. However, it may be possible to approach the question of the role of leptin in PCOS by ways other than the simple measurement of circulating leptin levels. It appears that leptin does not play a role in $\mathrm{LH}, \mathrm{FSH}$, androgen or lipid secretion in PCOS patients or in control subjects. However, a possible link between leptin and estradiol may exist. They were positively correlated in PCOS patients regardless of their weight.

\section{References}

1. Dunaif A (1992). Insulin resistance and ovarian hyperandrogenism. Endocrinologist, 2: 248-260.

2. Dunaif A (1994). Molecular mechanisms of insulin resistance in the polycystic ovary syndrome. Seminars in Reproduction and Endocrinology, 12: 15-20.

3. Green BB, Weiss NS \& Daling JR (1988). Risk of ovulatory infertility in relation to body weight. Fertility and Sterility, 50: 721-726.

4. Zhang $Y$, Proença R, Maffei M, Barone M, Leopold L \& Friedman JM (1994). Positional cloning of the mouse obese gene and its human homologue. Nature, 372: 425-432.

5. Considine RV, Sinha MK, Heiman ML, Kriaugiunas A, Stephens TW, Nyce MR, Ohannesian JP, Marco CC, McKee LJ \& Bauer TL (1996). Serum immunoreactive-leptin concentrations in normal-weight and obese humans. New England Journal of Medicine, 334: 292-295.

6. Halaas JL \& Friedman JM (1997). Leptin and its receptor. Journal of Endocrinology, 155: 215-216

7. Cusin I, Dryden S, Wang Q, Rohner-Jeanrenaud F, Jeanrenaud B \& Williams G (1995). Effect of sustained physiological hyperinsulinaemia on hypothalamic neuropeptide $Y$ and NPY mRNA levels in the rat. Journal of Neuroendocrinology, 7: 193-197.

8. Kolaczynski JW, Nyce MR, Considine RV, Boden G, Nolan JJ, Henry R, Mudaliar SR, Olefsky J \& Caro JF (1996). Acute and chronic effects of insulin on leptin production in humans: studies in vivo and in vitro. Diabetes, 45: 699-701.

9. Poretsky L, Cataldo NA, Rosenwaks Z \& Giudice LC (1999). The insulin-related ovarian regulatory system in health and disease. Endocrine Reviews, 20: 535-582.

10. Brzechffa PR, Jakimiuk AJ, Agarwal SK, Weitsman SR, Buyalos RP
\& Magoffin DA (1996). Serum immunoreactive leptin concentrations in women with polycystic ovary syndrome. Journal of Clinical Endocrinology and Metabolism, 81: 4166-4169.

11. Mantzoros CS, Dunaif A \& Flier JS (1997). Leptin concentrations in the polycystic ovary syndrome. Journal of Clinical Endocrinology and Metabolism, 82: 1687-1691.

12. Pirwany IR, Fleming R, Sattar N, Greer IA \& Wallace AM (2001). Circulating leptin concentrations and ovarian function in polycystic ovary syndrome. European Journal of Endocrinology, 145: 289-294.

13. Telli MH, Yildirim M \& Noyan V (2002). Serum leptin levels in patients with polycystic ovary syndrome. Fertility and Sterility, 77: 932-935.

14. Keys A, Fidanza F, Karvonen MJ, Kimura N \& Taylor HL (1972). Indices of relative weight and obesity. Journal of Chronic Diseases, 25: 329-343.

15. American Diabetes Association Clinical Practice Recommendations (2000). Gestational diabetes mellitus. Diabetes Care, 23: 77-79.

16. Shimizu H, Shimomura Y, Nakanishi Y, Futawatari T, Ohtani K, Sato N \& Mori M (1997). Estrogen increases in vivo leptin production in rats and human subjects. Journal of Endocrinology, 154: 285-292.

17. Messinis IE, Milingos S, Zikopoulos K, Kollios G, Seferiadis K \& Lolis $D$ (1998). Leptin concentrations in the follicular phase of spontaneous cycles and cycles superovulated with follicle stimulating hormone. Human Reproduction, 13: 1152-1156.

18. Sun F \& Yu J (2000). The effect of a special herbal tea on obesity and anovulation in androgen-sterilized rats. Proceedings of the Society for Experimental Biology and Medicine, 223: 295-301.

19. Ainslie DA, Morris MJ, Wittert G, Turnbull H, Projetto J \& Thorbum 
AW (2001). Estrogen deficiency causes central leptin-insensitivity and increased hypothalamic neuropeptide Y. International Journal of Obesity and Related Metabolic Disorders, 25: 680-688.

20. Rosenbaum M, Nicolson M, Hirsch J, Heymsfield SB, Gallagher D, Chu F \& Leibel RL (1996). Effects of gender, body composition, and menopause on plasma concentrations of leptin. Journal of Clinical Endocrinology and Metabolism, 81: 3424-3427.

21. Castracane VD, Kraemer RR, Franken MA, Kraemer GR \& Gimpel $T$ (1998). Serum leptin concentration in women: effect of age, obesity, and estrogen administration. Fertility and Sterility, 70: 472-477.

22. Licinio J, Negrao AB, Mantzoros C et al. (1998). Sex differences in circulating human leptin pulse amplitude: Clinical implications. Journal of Clinical Endocrinology and Metabolism, 83: 4140-4147.

23. Tanaka M, Nakava S, Kurnai T, Watanabe M, Taeish T, Shimizu H \& Kobayashi S (2001). Effects of estrogen on serum leptin levels and leptin mRNA expression in adipose tissue in rats. Hormone Research, 56: 98-104.

24. Zachow RJ \& Magoffin DA (1997). Direct intraovarian effects of leptin: impairment of the synergistic action of insulin-like growth factor-I on follicle-stimulating hormone-dependent estradiol-17 beta production by rat ovarian granulosa cells. Endocrinology, 138: 847850.

25. Karlsson $C$, Lindell $K$, Svensson E, Bergh $C$, Lind $P$, Billig $H$, Carlsson LM \& Carlsson B (1997). Expression of functional leptin receptors in the human ovary. Journal of Clinical Endocrinology and Metabolism, 82: 4144-4148.

26. Taylor AE, McCourt B, Martin KA, Anderson EJ, Adams JM, Schoenfeld D \& Hall JE (1997). Determinants of abnormal gonadotrophin secretion in clinically defined women with polycystic ovary syndrome. Journal of Clinical Endocrinology and Metabolism, 82: 2248-2256.

27. Laughlin GA, Morales AJ \& Yen SS (1997). Serum leptin levels in women with polycystic ovary syndrome: the role of insulin resistance/hyperinsulinemia. Journal of Clinical Endocrinology and Me- tabolism, 82: 1692-1696.

28. Kopelman PG (1994). Hormones and obesity. Baillieres Clinical Endocrinology and Metabolism, 8: 549-575

29. Maggio CA \& Pi-Sunyer FX (1997). The prevention and treatment of obesity. Diabetes Care, 20: 1744-1766.

30. Micic D, Macut D, Popovic V, Sumarac-Dumanovic M, Kendereski A, Colic M, Dieguez C \& Casanueva FF (1997). Leptin levels and insulin sensitivity in obese and non-obese patients with polycystic ovary syndrome. Gynecology and Endocrinology, 11: 315-320.

31. Saad MF, Khan A, Sharma A, Michael R, Riad-Gabriel MG, Boyadjian R, Jinagouda SD, Steil GM \& Kamdar V (1998). Physiological insulinemia acutely modulates plasma leptin. Diabetes, 47: 544549.

32. Fernandez-Real JM, Casamitjana R \& Ricart-Engel W (1998). Leptin is involved in gender-related differences in insulin sensitivity. Clinical Endocrinology, 49: 505-511.

33. Gennarelli G, Holte J, Wide L, Berne C \& Lithell H (1998). Is there a role for leptin in the endocrine and metabolic aberrations of polycystic ovary syndrome? Human Reproduction, 13: 535-541.

34. Escobar-Morreale HF, Serrano-Gotarredona J, Varela C, Garcia-Robles R \& Sancho JM (1997). Circulating leptin concentrations in women with hirsutism. Fertility and Sterility, 68: 898-906.

35. Rouru J, Anttila L, Koskinen P, Penttila TA, Irjala K, Huupponen R \& Koulu M (1997). Serum leptin concentrations in women with polycystic ovary syndrome. Journal of Clinical Endocrinology and Metabolism, 82: 1697-1700.

36. Spritzer PM, Poy M, Wiltgen D, Mylius LS \& Capp E (2001). Leptin concentrations in hirsute women with polycystic ovary syndrome or idiopathic hirsutism: influence on $\mathrm{LH}$ and relationship with hormonal, metabolic, and anthropometric measurements. Human Reproduction, 16: 1340-1346.

37. Messinis IE \& Millings SD (1999). Leptin in human reproduction. Human Reproduction Update, 5: 52-63 (Review). 